\title{
Synthesis of Nanocomposites Based on
}

Mesoporous Aluminosilicate and Polyethyleneimine (PEI) for siRNA Delivery: Potential Usefulness of the Synergistic Effect of $\mathrm{Al}^{3+}$ ion and PEl on the siRNA Delivery Efficiency for Diseases Treatment

Rafaatossadat Badihi

Islamic Azad University Tehran North Branch

Ali Mahmoudi

Islamic Azad University Tehran North Branch

Mohammad Reza Sazegar ( $\sim$ m_r_sazegar@yahoo.com )

Islamic Azad University Tehran North Branch https://orcid.org/0000-0001-6766-4643

khodadad Nazari

National Bioenergy Center

Research Article

Keywords: siRNA delivery, polyethyleneimine, Mesoporous silica nanoparticles, Aluminosilicate

Posted Date: June 23rd, 2021

DOl: https://doi.org/10.21203/rs.3.rs-628406/v1

License: (c) (i) This work is licensed under a Creative Commons Attribution 4.0 International License.

Read Full License 


\section{Abstract}

Several nanocomposites based on mesoporous silica nanoparticles (MSN), aluminium ions and Polyethyleneimine (PEI) were synthesized by the combination of the sol-gel and post-synthesis methods. These nanocomposites were mainly composed of MSN with the leading of Al and PEI species alone or combination. The AI-MSN, MSN-PEI, and Al-MSN/PEI samples were characterized by using FT-IR, XRD, SEM, EDX, zeta potential, and nitrogen physisorption techniques. The potential of their RNA delivery was investigated by loading and releasing of the siRNA in the phosphate buffer. The obtained results showed that the loading capacity of each sample is directly related to its zeta potential. The Al-MSN/PEI sample showed the highest siRNA adsorption capacity due to the possessing the highest zeta potential resulted the presence of the high electric charge of $\mathrm{Al}^{3+}$ and cationic nature of PEI. Under the optimized conditions, the Al-MSN/PEl sample showed the amount of $47.19 \mu \mathrm{g}$ adsorption of siRNA for $1.0 \mathrm{mg}$ of Al-MSN/PEI. The results of releasing siRNA exhibited the yields of $12,20.4,29.6$, and $36.0 \%$ for MSN, MSN-PEI, Al$\mathrm{MSN}$, and Al-MSN/PEI, respectively at room temperature for $120 \mathrm{~min}$.

\section{Introduction}

Mesoporous silica nanoparticles (MSNs) form an outstanding class of nanomaterials when their interesting properties such as high surface areas, large pore size and volume, tunable porosity, and thermal stability are considered [1]. The modification of the MSNs able to increase the activity of MSNs in the adsorption process due to the generation of the active sites on the surface of MSN. Introduction of transition metal ions such as cobalt in the MSN frameworks can be modified the mesoporous structure through the sol-gel method or by the impregnation technique [2-9]. Generally, MSN exhibit specific surface areas around $1000 \mathrm{~m}^{2} \mathrm{~g}^{-1}$, and this unique feature in combination with their high porosity provides a suitable platform for loading and delivery of large amounts of molecules [10-12]. Gene therapy has been recognized as one of the most potent therapies for the treatment of complex diseases such as cancer, cardiovascular disorders, and Alzheimer's disease [13-16]. Initiation and propagation of these diseases are based on the expression of certain genes that need to be silenced by the aid of small interfering RNA (siRNA) molecules. These are also known as short interfering RNA or silencing RNA, a class of doublestranded RNA and non-coding RNA molecules. They are typically made of 20-27 base pairs in length. They interfere with the expression of specific genes with complementary nucleotide sequences by degrading mRNA after transcription. siRNA may serve as the most appropriate tool for short term silencing of the protein-coding genes. Such therapy requires efficient gene delivery to cells because naked nucleic acids alone are not capable of getting across cell membranes $[17,18]$. Recently, some interesting methods for gene delivery have been introduced that included inorganic nanoparticles, liposomes, and polymer-based nanomaterials [19-22]. The good biocompatibility of the silica-based nanoparticles makes them a promising candidate for gene delivery $[23,24]$. Today, the attempts on developing silica-based gene delivery carriers are concentrated on two general aspects like surface chemistry and particle structure. From a surface chemistry point of view, before nucleic acid loading, an early modification step is required because the silica surface is negatively charged under biologically related conditions [25]. 
Different modifiers such as metal ions [26], amino silanes [27], cationic polymers [28,29], and peptides [30] have been used to change the surface charge of MSN. The modifier improves the interaction between DNA and MSN by reducing the electrostatic repulsion. Much attention has been paid to the modification of mesoporous silica materials and the enhancement of their adsorption capacity. Prabhakar and coworkers studied the effect of amino-functional groups on the surface of mesoporous silica material and enhanced the DNA binding via electrostatic interactions [31]. Keasberry et al. reported that the MSNs modified with polyamidoamine dendrimers have high adsorption capacity for plasmid DNA, and therefore have a higher ability to transfect HeLa cells [32]. Recently, MSN was modified with polyethyleniminepolyethylene glycol copolymers (PEI-PEG) and used as a co-deliver anticancer drug and siRNA into the breast cancer cells, in order to decrease the cells' potency to develop drug resistance [33]. In nanoparticlebased gene delivery systems, the nucleic acids were carried exclusively by the outer surface of the nanoparticles [34-37].

In recent years, Kumar and his co-workers synthesized a Mesoporous silica nanoparticle based enzyme for colon specific drug delivery through a natural carbohydrate polymer of guar gum capping. They showed that the MSN structure was remained after guar gum capping via non-covalent interaction. The result was manifested the release of 5-flurouracil as an anticancer drug in colon cancer cell lines in vitro which confirmed by biochemical assay and flow cytometry [38]. In another study, Wu et al., researched on the preparation of mesoporous polymer nanospheres (MPNs) as nanocarriers of B-cell lymphoma 2 (Bcl2) small interference RNA (siRNA) for breast cancer treatment. The FA-targeted-Bcl-2-siRNA-loaded nanoparticles were prepared via a layer-by-layer assembly through the electrostatic interactions. These nanoparticles showed anticancer effect was increased on breast cancer (BC) cells by a significant sequence-specific inhibition of Bcl-2 mRNA expression in the BC cells by cancer cell apoptosis [39]. Folic acid-loaded magnetic SBA-15 that incorporated with quercetin were synthesized to investigate human colorectal carcinoma cells (HCT-116). This composite caused the tumour suppression, and triggered mitochondrial-dependent apoptosis via a redox-regulated cellular signalling system [40].

In this study, we synthesized some nanocomposites based on the MSN which modified with aluminium, and polyethyleneimine (PEI) as the potential carriers for siRNA delivery. Their structures were characterized by using XRD, FTIR, SEM, BET, and TEM methods. In addition, the ability of their RNA delivery was investigated through the release of siRNA in the phosphate buffer solution (PBS, $\mathrm{pH}=7.2)$ at room temperature.

The important point of this study is that the aim of this research is merely to synthesize a nanocomposite based on mesoporous aluminosilicate nanoparticles and PEI polymer that carrier the siRNA. This study indicates that this nanocomposite with PEI polymer can be a good carrier for siRNA, and only the release of siRNA in the different alkali, acidic, and neutral media has been investigated. Therefore here, biological studies of the in vitro and in vivo tests have not been done on this nanocomposite.

\section{Experimental Section}




\subsection{Materials}

Tetraethylorthosilicate (TEOS, 98\%), cetyltrimethylammonium bromide (CTAB, 95\%), aminopropyltriethoxysilane (APTES, 99\%), phosphate buffer $(\mathrm{pH}=7.2)$, sodium hydroxide (extra pure), polyethyleneimine (MW $10 \mathrm{kD}$ ), and ethanol (99\%) were purchased from Sigma-Aldrich Co. The certain siRNA was purchased from Sinagene Co. (Tehran). All of the solvents and reagents were used as received without further purification. Double distilled water was used in all of the experiments. Aluminium nitrate nine hydrate $\left(\mathrm{Al}\left(\mathrm{NO}_{3}\right)_{3} \cdot 9 \mathrm{H}_{2} \mathrm{O}\right)$ was purchased from Merck Co.

\subsection{Methods}

\subsubsection{Synthesis of mesoporous silica nanoparticles (MSN)}

MSN samples were prepared according to the reported procedure [35]. A solution of CTAB $(10 \mathrm{~g})$ in double-distilled water $(275 \mathrm{ml})$ was prepared at room temperature. Then a solution of $25 \%$ ammonia (54 $\mathrm{ml})$ in ethanol $(395 \mathrm{ml})$ was added to the above-mentioned solution and the mixture was stirred for $5 \mathrm{~h}$. Finally, TEOS $(45 \mathrm{ml})$ was added to the mixture and stirred for $8 \mathrm{~h}$. The gel was aged for $8 \mathrm{~h}$. The precipitate was then washed with water and ethanol $(300 \mathrm{ml})$ of each sample, oven-dried, and finally calcined at $550^{\circ} \mathrm{C}$.

\subsubsection{Synthesis of Aluminium-modified mesoporous silica nanoparticles (AI-MSN)}

MSN $(0.1 \mathrm{~g})$ was added to $0.3 \mathrm{M} \mathrm{Al}\left(\mathrm{NO}_{3}\right)_{3} .9 \mathrm{H}_{2} \mathrm{O}$ in double-distilled water $(20 \mathrm{ml})$ and sonicated for 50 min. The mixture was then stirred at $70^{\circ} \mathrm{C}$ for $5 \mathrm{~h}$. Afterward, the precipitate was filtered and washed three times with water, oven-dried at $90^{\circ} \mathrm{C}$ for $24 \mathrm{~h}$, and finally calcined at $650^{\circ} \mathrm{C}$ for $3 \mathrm{~h}$. The obtained sample was denoted as Al-MSN $[41,42]$.

\subsubsection{Synthesis of PEI-modified MSN and Al-MSN}

The PEl-modified MSN and Al-MSN samples were obtained as follows: the amount of $5.0 \mathrm{mg}$ of each sample was dispersed into the absolute ethanol $(1.0 \mathrm{~mL})$ and sonicated for $15 \mathrm{~min}$. Then polyethyleneimine (PEI, MW $10 \mathrm{kD}, 2.5 \mathrm{mg}$ ) was added to the dispersion and the mixture was stirred at room temperature for $15 \mathrm{~h}$. The PEl-modified particles were collected by centrifugation, washed with absolute ethanol and distilled water $(3 \times 10 \mathrm{ml})$, and finally dried at room temperature. The samples were denoted as MSN-PEI and Al-MSN/PEI.

\subsection{4 siRNA loading and release}

The amount of siRNA was loaded on the MSN surface and monitored by using a UV-vis spectrophotometer. Typically, $10 \mathrm{mg}$ of each sample was added to $10 \mathrm{ml}$ of a $150 \mu \mathrm{g} / \mathrm{mL}$ solution of the siRNA in PBS (pH 7.2) and stirred at room temperature for $2 \mathrm{~h}$. At given time intervals, the amount of the adsorbed siRNA on each sample was determined at $\lambda \max$ of $260 \mathrm{~nm}$. The release of the siRNA was studied on the concentrations of $1,5,25,50,75,100$, and $150 \mathrm{\mu g} \mathrm{ml}^{-1}$ of siRNA, in phosphate buffer 
solution at $260 \mathrm{~nm}$. The siRNA concentration was calculated as: [siRNA] $=0.0192 \times A b s(260)-0.037,\left(R^{2}\right.$ $=0.998)$, where Abs(260) stands for the absorbance of the solution at $260 \mathrm{~nm}$.

\subsection{Characterization of the nanocomposites}

Fourier-transform infrared (FT-IR) spectra were recorded using KBr disks on a Rayleigh, WQF-510 infrared spectrophotometer. Ultraviolet-visible (UV-vis) absorption spectra were recorded on a Varian Cary 100 spectrophotometer in quartz cuvettes. Zeta potential measurements were performed on a Zetasizer Nano ZS (Malvern, Instruments, and Westborough, MA) with a backscattering detection at $173^{\circ}$. Powder X-ray diffraction (XRD) data were collected with a Philips PW 1830 diffractometer (Cu-Ka X-radiation, $\lambda=1.54$ $\AA$ A). SEM imaging was performed on a JEOL JEM-2100 transmission electron microscope. $\mathrm{N}_{2}$ adsorptiondesorption isotherms were measured at $77 \mathrm{~K}$ on a BELSORP MINI II instrument. Samples were degassed in a vacuum and annealed at $120^{\circ} \mathrm{C}$ for at least $6 \mathrm{~h}$ to remove moisture. The pore size distribution was evaluated by using the Barrett-Joyner-Halenda (BJH) model.

\section{Results And Discussion}

\subsection{Characterizations of the nanocomposites}

The FT-IR spectra of the MSN, Al-MSN, MSN-PEI, and AI-MSN/PEI samples are shown in Fig. 1. The broad bands at about $3452 \mathrm{~cm}^{-1}$ are attributed to the $\mathrm{O}-\mathrm{H}$ stretching vibrations of either silanol groups or adsorbed water [25-43]. The $0-\mathrm{H}$ and Si-O-Si bending vibrations have also appeared at $1640 \mathrm{~cm}^{-1}$. The symmetric and asymmetric $\mathrm{Si}-\mathrm{O}-\mathrm{Si}$ stretching vibrations were observed around the region of 1082 and $802 \mathrm{~cm}^{-1}$, respectively [25]. Two weak peaks of the C-H stretching vibrations are visible at about 2970 and $2890 \mathrm{~cm}^{-1}$ which are attributed to the presence of the PEI molecules in the MSN-PEI and AI-MSN/PEI samples [41-43]. Metal-oxide vibrations of either $\mathrm{Si}^{4+}$ or $\mathrm{Al}^{3+}$ species in tetrahedral holes also appeared at $467 \mathrm{~cm}^{-1}$ [43]. Although the $\mathrm{C}-\mathrm{N}$ stretching vibrations of the PEl are anticipated to appear in the range of $1000-1250 \mathrm{~cm}^{-1}$, these were overlapped with the strong peaks of the Si-O-Si vibrations [43]. It can be concluded that PEI modification was successfully achieved and no considerable change in the metaloxide bands were occurred.

The low and high angle XRD patterns for the MSN, AI-MSN, MSN-PEI, and Al-MSN/PEI are presented in Fig. 2. In all cases, a broad peak was observed at about $22^{\circ}$, which originates from amorphous silica [2]. In the low angle XRD patterns, three diffraction peaks of 100,110 , and 200 were observed at $2.65^{\circ}, 4.3^{\circ}$, and $4.8^{\circ}$, respectively, for the MSN (Fig. 2A). These peaks are indicative of the mesoporous silica structure $[36,37]$. The intensity of these peaks were decreased after incorporating the metal and organic compounds which showed the less order mesoporous structure for these nanomaterials [2, 43].

The morphology of the MSN, MSN-PEI, Al-MSN, and Al-MSN/PEI samples was studied by SEM imaging (Fig. 3). All of the samples were made of uniform spherical particles in the range of 70-180 nm [2]. It is 
also noteworthy that PEl treatment did not change the morphology of the products as it is evident from Fig. 3b, and 3d.

The presence and homogeneity distribution of Al ions in the AI-MSN/PEI sample were investigated by EDX and mapping, respectively. Fig. 4a shows a homogeneous distribution of $\mathrm{Al}^{3+}$ in its mesoporous silica and Fig. $4 \mathrm{~b}$ is evidence of the presence of $\mathrm{Si}, \mathrm{O}$, and Al species in Al-MSN/PEI.

The nitrogen adsorption-desorption isotherms and pore size distribution of the samples are shown in Fig. 5. All of the samples showed a type IV isotherm with distinct $H 4$ hysteresis loops in the $\mathrm{p} / \mathrm{p}_{0}$ range of 0.3 1.0 (Fig. 5A). The narrow pore size distribution of the samples are observed around $1.2 \mathrm{~nm}$ (Fig. 5B).

Table 1 Physicochemical properties of the MSN, MSN-PEI, Al-MSN, and Al-MSN/PEl samples

\begin{tabular}{llll} 
Catalyst & $\mathbf{S}^{\mathbf{a}}\left(\mathbf{m}^{2} \mathbf{g}^{-1}\right)$ & $\mathbf{V}_{\mathbf{p}}^{\mathbf{b}}\left(\mathbf{c m}^{3} \mathbf{g}^{-1}\right)$ & $\mathbf{W}^{\mathbf{c}}(\mathbf{n m})$ \\
\hline MSN & 1062 & 0.53 & 2.00 \\
\hline Al-MSN & 691 & 0.36 & 2.10 \\
\hline MSN-PEI & 522 & 0.33 & 2.50 \\
\hline Al-MSN/PEI & 393 & 0.34 & 3.44
\end{tabular}

${ }^{a} S$, Surface area obtained from $N_{2}$ adsorption-desorption isotherms; ${ }^{b} V_{p}$ Total pore volume; ${ }^{c} W$ Pore diameter

The surface area of the MSN was reduced upon modification with either $\mathrm{Al}^{3+}$ or PEI $\left(1062 \mathrm{~m}^{2} \mathrm{~g}^{-1}\right.$ for MSN vs. 691,552 , and $393 \mathrm{~m}^{2} \mathrm{~g}^{-1}$ for the Al-MSN, MSN-PEI, and Al-MSN/PEI samples, respectively). Conversely, the total pore volume of the MSN was reduced after modification from $0.53 \mathrm{~cm}^{3} \mathrm{~g}^{-1}$ for MSN to $0.34 \mathrm{~cm}^{3} \mathrm{~g}$ 1 for Al-MSN/PEI which may be due to partial pore blockage by $\mathrm{PEI}, \mathrm{Al}^{3+}$, or both of them [6]. The pore size was also increased upon modification with Al3+ and PEl from $2.00 \mathrm{~nm}$ for MSN to $3.44 \mathrm{~nm}$ for AlMSN/PEI.

\subsection{Zeta potential measurements}

Zeta potential of the synthesized samples is presented in Fig. 6. The Zeta potential of the pure MSN was altered after introduction with aluminium ions and PEI species so the PEI-containing samples demonstrated positive zeta potentials [44]. The change in the zeta potential values from negative to positive indicated to increase in pure MSN surface isolation, due to the interactions between the MSN surface and PEI and aluminium ion modifiers [45]. The zeta potential of MSN was changed from -16.4 $\mathrm{mV}$ to $6.0 \mathrm{mV}$ after amination with PEl, making it possible to load siRNA molecules through the 
electrostatic attractions. Metal ions are also known to increase siRNA adsorption onto silica surfaces due to the mediation of the electrostatic repulsion between the negatively charged silica surface and the siRNA molecule [46].

Higher zeta potential of Al-MSN $(+26 \mathrm{mV})$ can be related to the electronic nature of the $\mathrm{Al}^{3+}$ ions which carries a high positive charge. $\mathrm{PEI}$, on the other hand, is a cationic polymer which induces a very positive charge on the modified MSN. Thus, we decided to use a combination of $\mathrm{PEI}$ and $\mathrm{Al}^{3+}$ to obtain the highest possible zeta potential. As anticipated, Al-MSN/PEl showed a high zeta potential of $54.1 \mathrm{mV}$, which confirmed that trivalent metals bind more strongly to siRNA [47].

\subsection{Loading and release of the siRNA}

The trend of the siRNA incorporation on the MSN and its modified forms was studied by UV-vis spectroscopy. First, a calibration curve was plotted according to the method described under the heading 2.2.4 (Fig. 7).

Fig. 8 illustrates the trend of siRNA loaded after each 120 min for the MSN, Al-MSN, MSN-PEI, and AlMSN/PEI samples. The adsorption capacity of the AI-MSN and MSN-PEI samples was higher than the pure MSN.

The adsorption capacity was improved when a combination of $\mathrm{Al}^{3+}$ and PEI was used. These observations are in agreement with the zeta potential values of the synthesized samples and the physicochemical properties (Table 1). The results showed although the MSN has the highest surface area and the highest monolayer adsorbed volume among the synthesized samples, it has the lowest siRNA adsorption capacity. Therefore, the adsorption capacity of the Al-MSN/PEI sample can be related to its physicochemical properties, including surface area, pore volume and pore diameter. Under the optimized conditions, $47.19 \mu \mathrm{g}$ of the siRNA was loaded on $1.0 \mathrm{mg}$ of the Al-MSN/PEl, after $90 \mathrm{~min}$, which is a promising result.

The siRNA release was investigated in a PBS $(10 \mathrm{ml})$ at $260 \mathrm{~nm}$, and at room temperature. The results were calculated as $1-\left(A_{1} / A_{0}\right)$, where $A_{0}$ is the absorbance of the siRNA standard solution and $A_{1}$ is the absorbance of siRNA in the filtrate. Fig. 9 depicts the trend of the siRNA release for $120 \mathrm{~min}$ from the AlMSN, MSN-PEI, and Al-MSN/PEI samples. The sharp release of the siRNA was observed for all of the samples in the first $20 \mathrm{~min}$. The pure MSN showed a release efficiency of about $13 \%$ of its initial siRNA loading after $120 \mathrm{~min}$.

The MSN modification with aluminium or PEl alone or together had a significant positive effect on the release efficiency of the siRNA. The results showed 22, 30, and 36\% siRNA release for the Al-MSN, MSN$\mathrm{PEI}$, and Al-MSN/PEl samples, respectively. According to the obtained results, the nanocomposite of AlMSN/PEl exhibited the highest release due to the possessing the highest zeta potential on the surface of this composite. 
Since the MSN surface and the siRNA chain possess negative charge at neutral media [48], the pure MSN cannot strongly adsorb the siRNA chain due to the repulsion force between these two materials [49]. The formation of bonds occurred among the molecules with donor electron atoms and also phosphate groups in the siRNA chain with the $\mathrm{Al}^{3+}$ atoms in the nanomaterial structure [34]. The phosphate buffer solution reduced the interaction between the metal ions and the siRNA species which results in the release of the siRNA molecules.

According to the Hard and Soft Acids and Bases (HSAB) theory, hard acids tend to hard bases and soft acids prefer binding with the soft bases. $\mathrm{Al}^{3+}$ is known as a hard acid due to its high positive charge and small radius, and it can easily form a stable complex with a phosphate group of the siRNA molecule. It is worth noting that the siRNA delivery systems are actively pursued by researchers around the world. A comparison of our results with the reported methods on siRNA delivery is summarized in Table 2.

In comparison with the other reported nanoparticles as siRNA carriers, Al-MSN/PEI nanoparticles show many advantages including ease of work-up, high performance in siRNA loading and release, and the use of affordable and non-toxic raw materials. The synthesized nanocomposites were able to undertake gene delivery in a high yield for the first time, and have superiority in comparison to the other reported nanomaterials. Another important advantage of our protocol is working at neutral $\mathrm{pH}$. For example, calcium phosphate nanoparticles 53 as siRNA carriers need the $\mathrm{pH}$ of solution to be adjusted at 4.0.

Table 2 A comparison of modified MSNs with the other vehicles for the siRNA delivery

\begin{tabular}{lllll} 
Sample & Temp. & $\begin{array}{l}\text { Loading } \\
\left(\begin{array}{l}\left.{ }^{\circ} \mathbf{C}\right) \\
(\%)\end{array}\right.\end{array}$ & $\begin{array}{l}\text { Release } \\
(\%)\end{array}$ & Ref. \\
\hline Al-MSN/PEI & 25 & 31.4 & 36 & This study \\
\hline Mannitol & 25 & 2 & 2 & 50 \\
\hline Human Serum Albumin & 37 & 8 & 40 & 51 \\
\hline PLGA & 25 & 2 & 57 & 52 \\
\hline Chitosan nanoparticles (lonic cross-linking) & 25 & 8.3 & 9.5 & 53 \\
\hline Chitosan nanoparticles (lonic gelation with TPP) & 25 & 10 & 12 & 53 \\
\hline Mesoporous glass nanoparticles & 25 & 2.5 & 40 & 54 \\
\hline Titania Nanotubes & 25 & 2.2 & 90 & 55 \\
\hline Calcium phosphate nanoparticles & 25 & - & 30 & 56
\end{tabular}

\section{Conclusions}


Mesoporous silica nanomaterials were synthesized and modified with aluminium and polyethyleneimine (PEI) to obtain suitable scaffolds for delivery of the siRNA chain. All of the synthesized samples were characterized by various techniques such as FT-IR, SEM, EDX, XRD, BET analysis. Zeta potential measurements showed that the loading of aluminium ions and PEI molecules to the MSN nanoparticles increased the zeta potential of the synthesized nanomaterials. The observed release efficiency for the MSN, MSN-PEI, AI-MSN, and Al-MSN/PEI nanocomposites were 12, 20.4, 29.6, and 36\%, respectively. Obviously, the Al-MSN/PEI nanocomposite showed the highest release efficiency. Al-MSN/PEI showed the highest zeta potential and exhibits the highest adsorption capacities among the synthesized samples. It was also found that the efficiency of the siRNA release from Al-MSN/PEl is just as good as its adsorption. The present study aimed to extend the applications of the mesoporous silica nanoparticles to the treatment of the deadly diseases of the $21^{\text {st }}$ century, including Alzheimer's disease, cancer, AIDS, etc. Although the gene silencing mediated by double-stranded small interfering RNA (siRNA) has been widely investigated as a potential therapeutic approach, its usage is hampered by its rapid degradation and poor cellular uptake into cells in vitro or in vivo. Therefore, we used MSNs as a siRNA vector due to their advantages such as low toxicity and biocompatibility. The results of the present study may provide a practical solution for siRNA purification techniques. Additionally, the Al-MSN/PEI nanocomposite can be utilized in the treatment or monitoring of gene-related diseases.

The essential purpose of this study is only to prepare a nanocomposite based on mesoporous aluminosilicate nanoparticles modified with PEI polymer that able to transfer the siRNA. The release of the loaded siRNA was studied in three conditions the alkaline, acidic, and neutral media. The results indicated that about $36 \%$ release of siRNA has happened. According to the obtained results, the certain siRNA can be loaded in the modified mesoporous silica nanomaterials which able to do certain gene delivery or for silencing some gene through this type of nanocomposite. To find the capability of this nanocomposite in the treatment of some diseases such as cancer, inflammatory and etc. through the gene or drug delivery, it is necessary to carry out the in vitro and/or in vivo biological studies.

\section{Declarations}

\section{Conflicts of Interest}

The authors declare no conflicts of interest.

\section{Ethics approval and consent to participate}

Not applicable

\section{Consent for publication}

Not applicable

\section{Funding}


There is no funding for this research.

\section{Conflicts of interest/Competing interests}

The authors declare that they have no known competing financial interests or personal relationships that could have appeared to influence the work reported in this paper.

\section{Availability of data and material}

The data and material used/analyzed during the current study are available from the corresponding author on request.

\section{Authors' contributions}

R. Badihi et al. contributed to the study conception and design. Samples preparation, data collection, and analysis were performed by R. Badihi, A. Mahmoudi, M.R. Sazegar, K. Nazari. The authors read and approved the final manuscript.

\section{Acknowledgments}

We thank the deputy of the research centre, Tehran North Branch, Islamic Azad University for helping to this study.

\section{References}

1. Sazegar MR, Mukti RR, Triwahyono S, Seyed Mohaghegh SM, Jalil AA, Aziz M (2015) New J. Chem., 39: 8006-8016.

2. Hajiagha NG, Mahmoudi A, Sazegar MR, Pouramini MM (2019) Microporous Mesoporous Mater., 274:43-53.

3. Todorova S, Parvulescu V, Kadinov G, Tenchev K, Somacescu S (2008) Microporous Mesoporous Mater., 113:22-30.

4. Popova M, Szegedi A, Cherkezova-Zheleva Z, Mitov I, Kostova N, Tsoncheva T, (2009) Hazard.Mater J 168 226-232.

5. Choopan Tayefe H, Sazegar MR, Mahmoudi A, Jadidi KH, (2019) J. Nanostruct, 9(4): 712-722.

6. Jamshidi D and Sazegar MR (2020) Int. J. Nanomedicine, 15:871-883.

7. Ortiz-Martinez K, Guerrero-Medina KJ, Roman FR, Hernandez-Maldonado AJ (2015) Chem. Engin. J., 264:152-164.

8. Vejdani Noghreiyan A, Sazegar MR, Mousavi Shaegh SA, Sazgarnia A (2020) Photodiagn. Photodyn. Ther., 30: 101770.

9. Sazegar MR, Dadvand A, Mahmoudi A (2017) RSC Adv., 7: 27506-27514.

10. Tang F, Li L, Chen D (2012) Adv. mater., 24: 1504-1534. 
11. Trofimov AD, Ivanova AA, Zyuzin MV, Timin AS (2018) Pharmaceutics, 10: 167.

12. Baeza A, Ruiz-Molina D, Vallet-Regí M (2017) Expert opin. drug deliv., 14: 783-796.

13. Verma IM, Naldini L, Kafri T, Miyoshi T, Takahashi M, Blömer U, Somia N, Wang L, Gage F, (2000) Genes and Resistance to Disease, Springer, pp. 147-157.

14. Pena SA, lyengar R, Eshraghi RS, Bencie N, Mittal J, Aljohani A, Mittal R, Eshraghi AA (2020) J. Drug Target., 28: 111-128.

15. Wang K, Kievit FM, Zhang M (2016) Pharmacol. Res., 114: 56-66.

16. Junquera E, Aicart E (2016) Adv. colloid interface sci., 233: 161-175.

17. Kim MH, Na HK, Kim YK, Ryoo SR, Cho HS, Lee KE, Jeon H, Ryoo R, Min DH (2011) ACS nano, 5: 3568-3576.

18. Chen J, Guo Z, Tian H, Chen X, Ther M (2016) Methods Clin. Dev., 3: 16023.

19. Zeng H, Little HC, Tiambeng TN, Williams GA, Guan Z, Am J (2013) Chem. Soc., 135: 4962-4965.

20. Zhang Y, Ren K, Zhang X, Chao Z, Yang Y, Ye D, Dai Z, Liu Y, Ju H (2018) Biomaterials, 163: 55-66.

21. Van Bruggen C, Hexum JK, Tan Z, Dalal RJ, Reineke TM (2019) Acc.Chem. Res., 52: 1347-1358.

22. Li Z, Zhang Y, Feng N (2019) Expert opin. drug deliv., 16: 219-237.

23. Zhou Y, Quan G, Wu Q, Zhang Z, Niu B, Wu B, Huang Y, Pan X, Wu C (2018) Acta pharm. Sin. B, 8: 165177.

24. Shao D, Lu Mm, Zhao Yw, Zhang F, Tan Yf, Zheng Z, Pan Y, Xiao Xa, Wang Z, Dong Ef (2017) Acta biomater., 49: 531-540.

25. Niu B, Zhou Y, Wen T, Quan G, Singh V, Pan X, Wu C (2018) Colloids Surf. A Physicochem. Eng. Asp., 548: 98-107.

26. Kamarudin NHN, Jalil AA, Triwahyono S, Sazegar MR, Hamdan S, Baba S, Ahmad A (2015) RSC Adv., 5, 30023-30031.

27. Topuz F, Uyar T (2018) Beilstein J. Nanotechnol., 9: 693-703.

28. Vathyam R, Wondimu E, Das S, Zhang C, Hayes S, Tao Z, Asefa T (2011) J. Phys. Chem. C, 115: 13135-13150.

29. Lo KH, Chen MC, Ho RM, Sung HW (2009) Acs Nano, 3: 2660-2666.

30. Cheng YJ, Zhang AQ, Hu JJ, He F, Zeng X, \& Zhang XZ (2017) ACS Appl. Mater. Interfaces, 9(3), 2093-2103.

31. Prabhakar N, Zhang J, Desai D, Casals E, Gulin-Sarfraz T, Näreoja T, Westermarck J, Rosenholm JM (2016) Int. J. Nanomedicine, 11: 6591.

32. Keasberry N, Yapp C, Idris A (2017) Biochemistry (Moscow), 82: 655-662.

33. Teo PY, Cheng W, Hedrick JL, Yang YY (2016) Adv. Drug Deliv. Rev., 98: 41-63.

34. Jiang S, Zhuang J, Wang C, Li J, Yang W (2012) Colloids Surf. A Physicochem. Eng. Asp., 409: 143148.

35. Sazegar MR, Dadvand A, Mahmoudi A (2017) RSC adv., 7: 27506-27514. 
36. Sazegar MR, Triwahyono S, Jalil AA, Mukti RR, Mohaghegh SMS, Aziz M (2015) New J. Chem., 39: 8006-8016.

37. Sazegar MR, Mahmoudian S, Mahmoudi A, Triwahyono S, Jalil AA, Mukti RR, Kamarudin NHN, Ghoreishi MK (2016) RSC adv., 6: 11023-11031.

38. Kumar B, Kulanthaivel S, Mondal A, Mishra S, Banerjee B, Bhaumik A, Banerjee I, Giri S (2017) Colloids and Surfaces B: Biointerfaces, 150: 352-361.

39. Wu X, Zheng Y, Yang D, Chen T, Feng B, Weng J, Wang J, Zhang K, Zhang X, Mater J (2019) Chem. B, 7: 477-487.

40. Mishra S, Manna K, Kayal U, Saha M, Chatterjee S, Chandra D, Hara M, Datta S, Bhaumik A, Das Saha K (2020) RSC Adv., 10: 23148-23164

41. Babaei M, Eshghi H, Abnous K, Rahimzadeh M, Ramezani M (2017) Cancer gene ther., 24: 156-164.

42. Ma Z, Guan Y, Liu H, Magn J. Magn (2006) Mater., 301: 469-477.

43. Sun XY, Li PZ, Ai B, Wang YB (2016) Chin. Chem. Lett., 27: 139-144.

44. Akbarzadeh M, Oskuee RK, Gholami L, Mahmoudi A, Malaekeh-Nikouei B (2019) J. Drug Deliv. Sci. Technol., 53: 101154.

45. Lindén JB, Larsson M, Kaur S, Nosrati A, Nydén M, Appl J (2016) Poly. Sci., 133.

46. Ganguly A, Ganguli AK (2013) Bull. Mater. Sci., 36: 329-332.

47. Zhang X, Zhang J, Quan G, Yang P, Pan X, Wu C (2017) AAPS Pharm.Sci.Tech., 18: 1536-1543.

48. He XX, Wang K, Tan W, Liu B, Lin X, He C, Li D, Huang S, Li J, Am J (2003) Chem. Soc., 125: 71687169.

49. Fujiwara M, Yamamoto F, Okamoto K, Shiokawa K, Nomura R (2005) Anal. Chem., 77: 8138-8145.

50. Chow MY, Qiu Y, Lo FF, Lin HH, Chan HK, Kwok PC, Lam JK (2017) Int. J. Pharm., 530: 40-52.

51. Chow MYT, Qiu Y, Liao Q, Kwok PCL, Chow SF, Chan HK, Lam JKW (2019) Int. J. Pharm., 572: 118818-118829.

52. Cun D, Jensen DK, Maltesen MJ, Bunker M, Whiteside P, Scurr D, Foged C, Nielsen HM (2011) Eur. J. Pharm. Biopharm., 77: 26-35.

53. Katas H, Alpar HO (2006) J. Control. Release, 115: 216-225.

54. ElpFiqi A, Kim TH, Kim M, Eltohamy M, Won JE, Lee EJ, Kim HW (2012) Nanoscale, 4: 7475-7488.

55. Song W, Zhao L, Fang K, Chang B, Zhang Y (2015) J. Mater. Chem. B, 3: 8567-8576.

56. Li J, Chen YC, Tseng YC, Mozumdar S, Huang L (2010) J. Control Release, 142: 416-421.

\section{Figures}




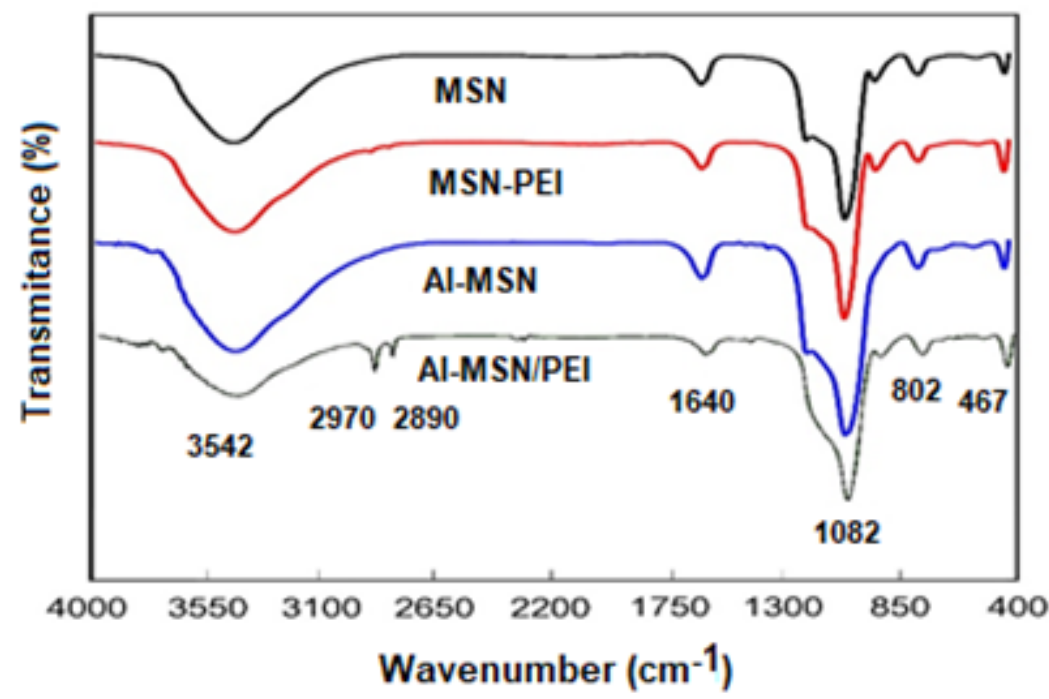

Figure 1

FTIR spectra of the MSN, MSN-PEI, Al-MSN, and Al-MSN/PEI samples
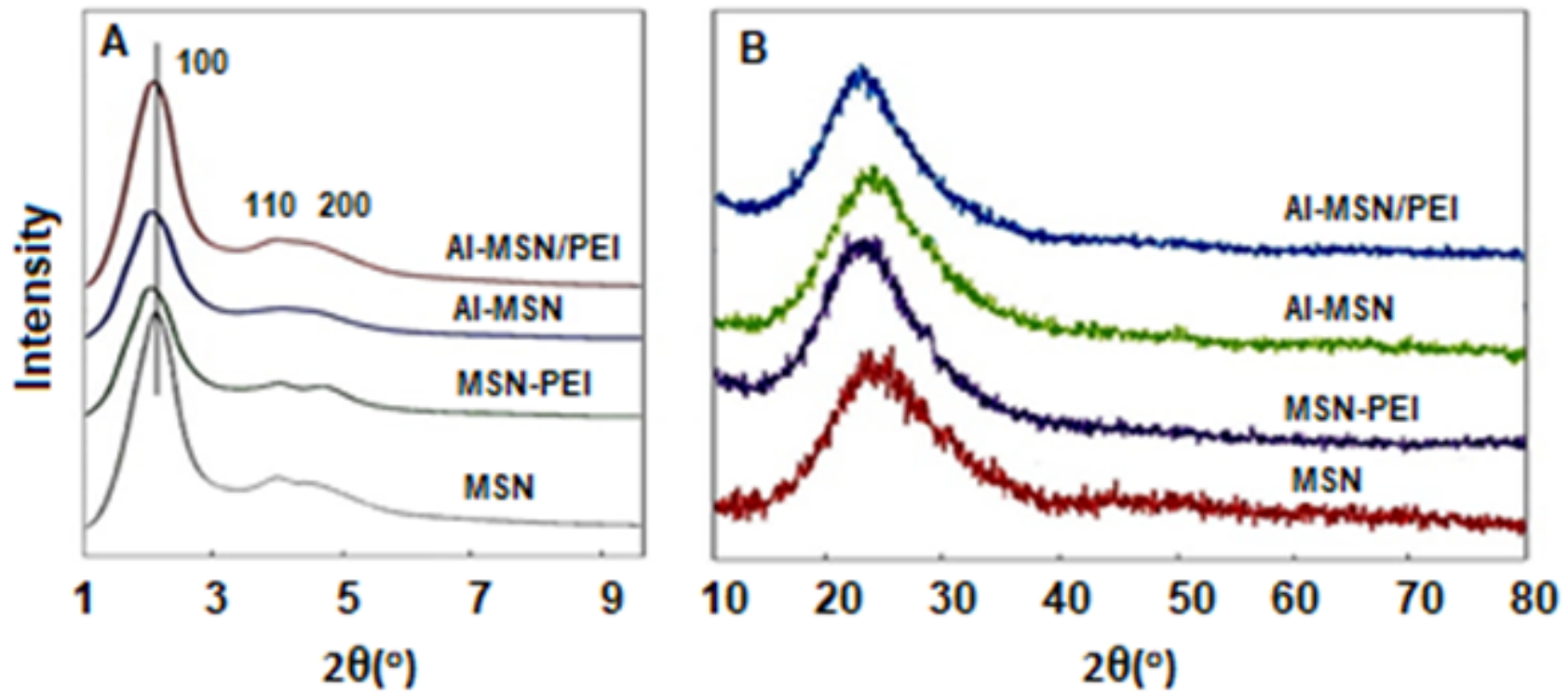

Figure 2

XRD patterns of the MSN, MSN-PEl, Al-MSN, and Al-MSN/PEl samples (A) Low angle, and (B) high angle 


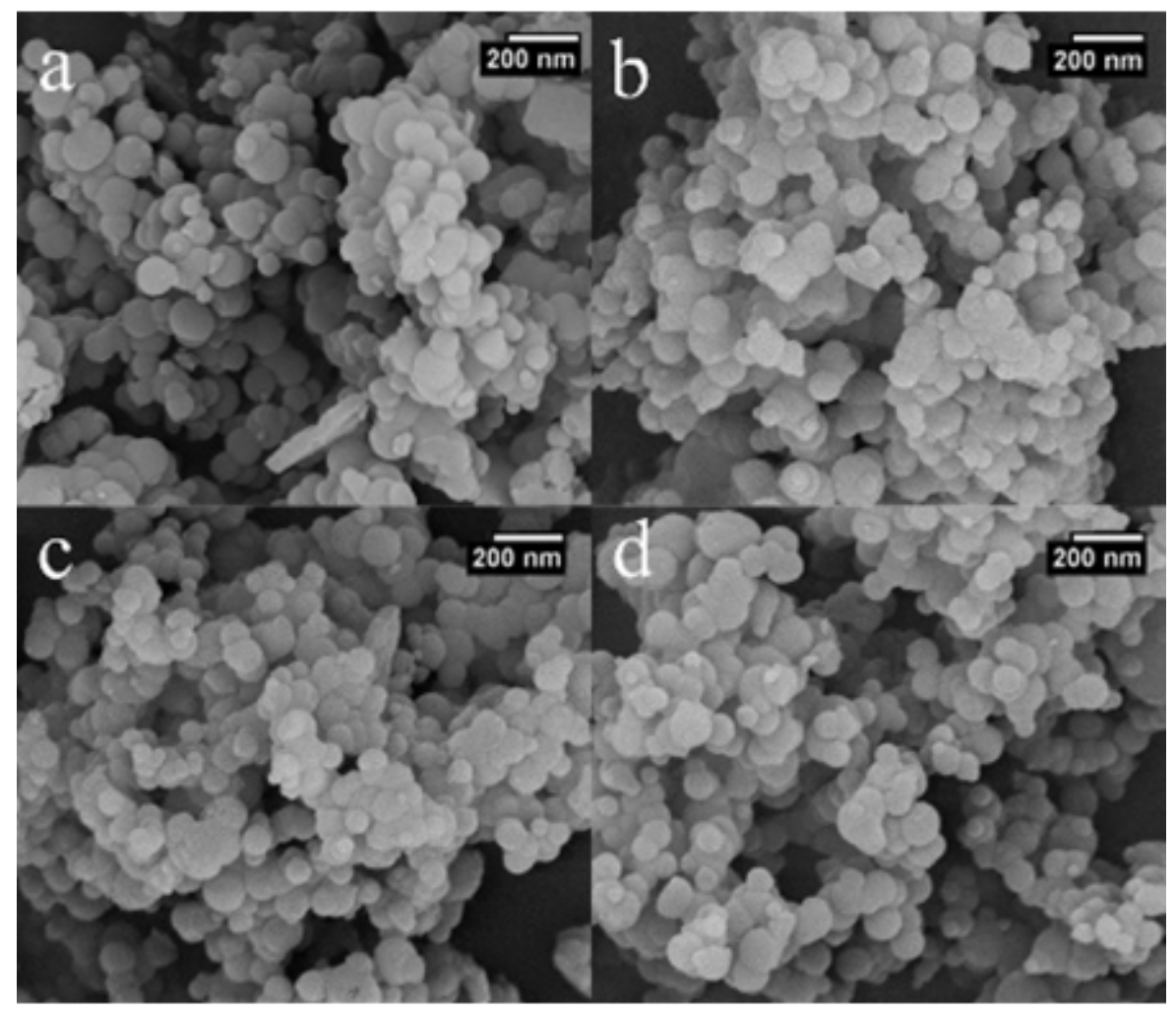

Figure 3

SEM images of a) MSN, b) MSN-PEI, c) Al-MSN, and d) Al-MSN/PEI
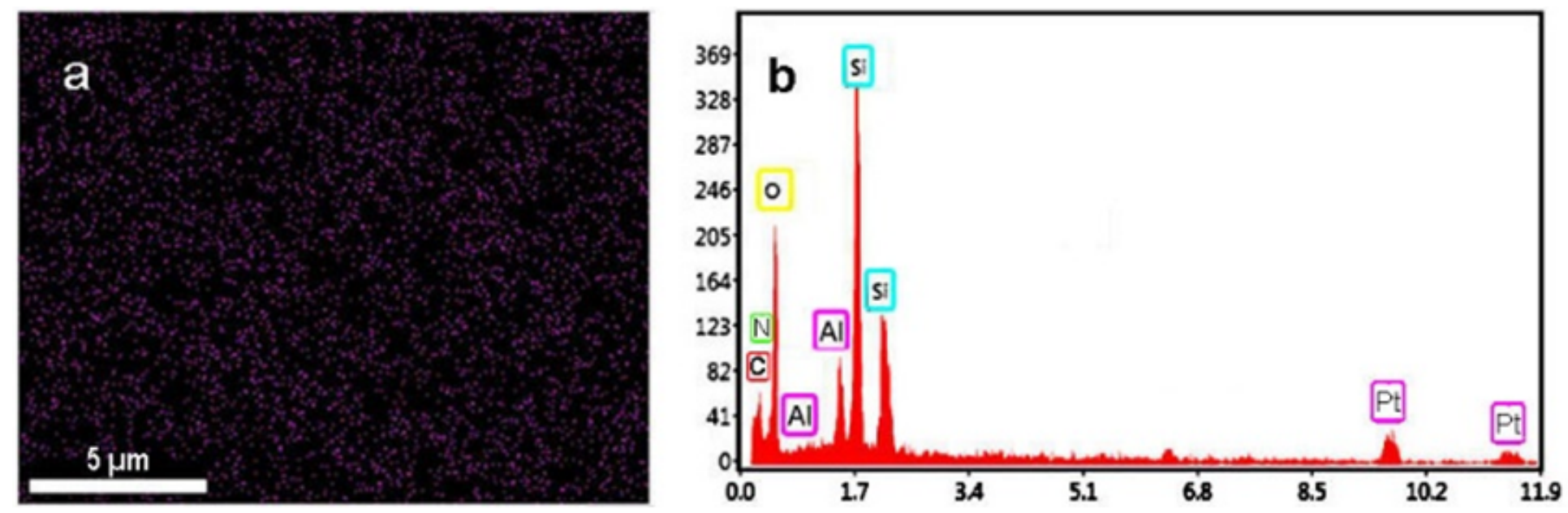

Figure 4

Mapping (a), and EDX (b) analysis of the Al-MSN/PEl sample 

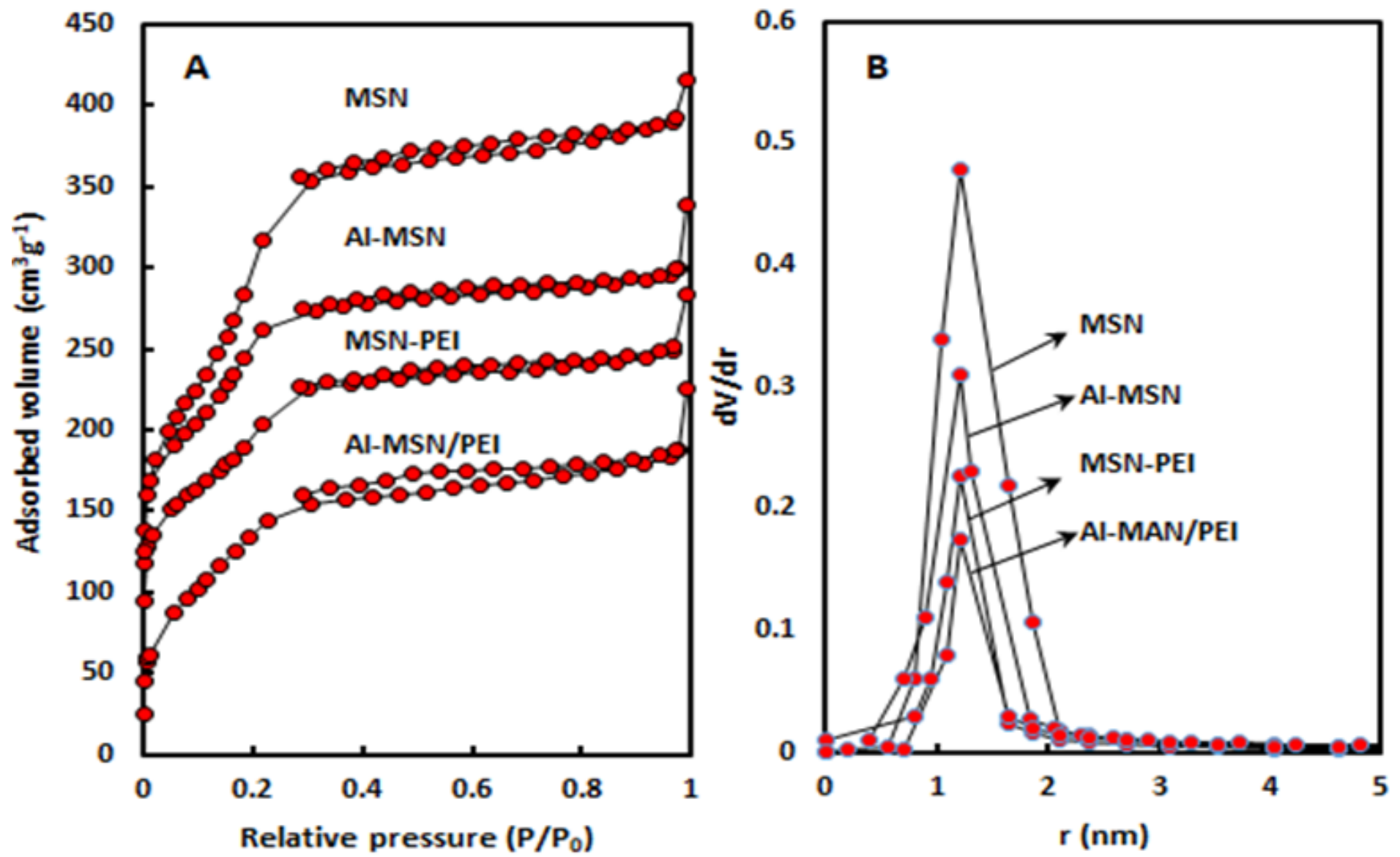

Figure 5

(A) Nitrogen adsorption-desorption isotherms, (B) Pore size distributions of MSN, MSN-PEl, Al-MSN, and Al-MSN/PEI

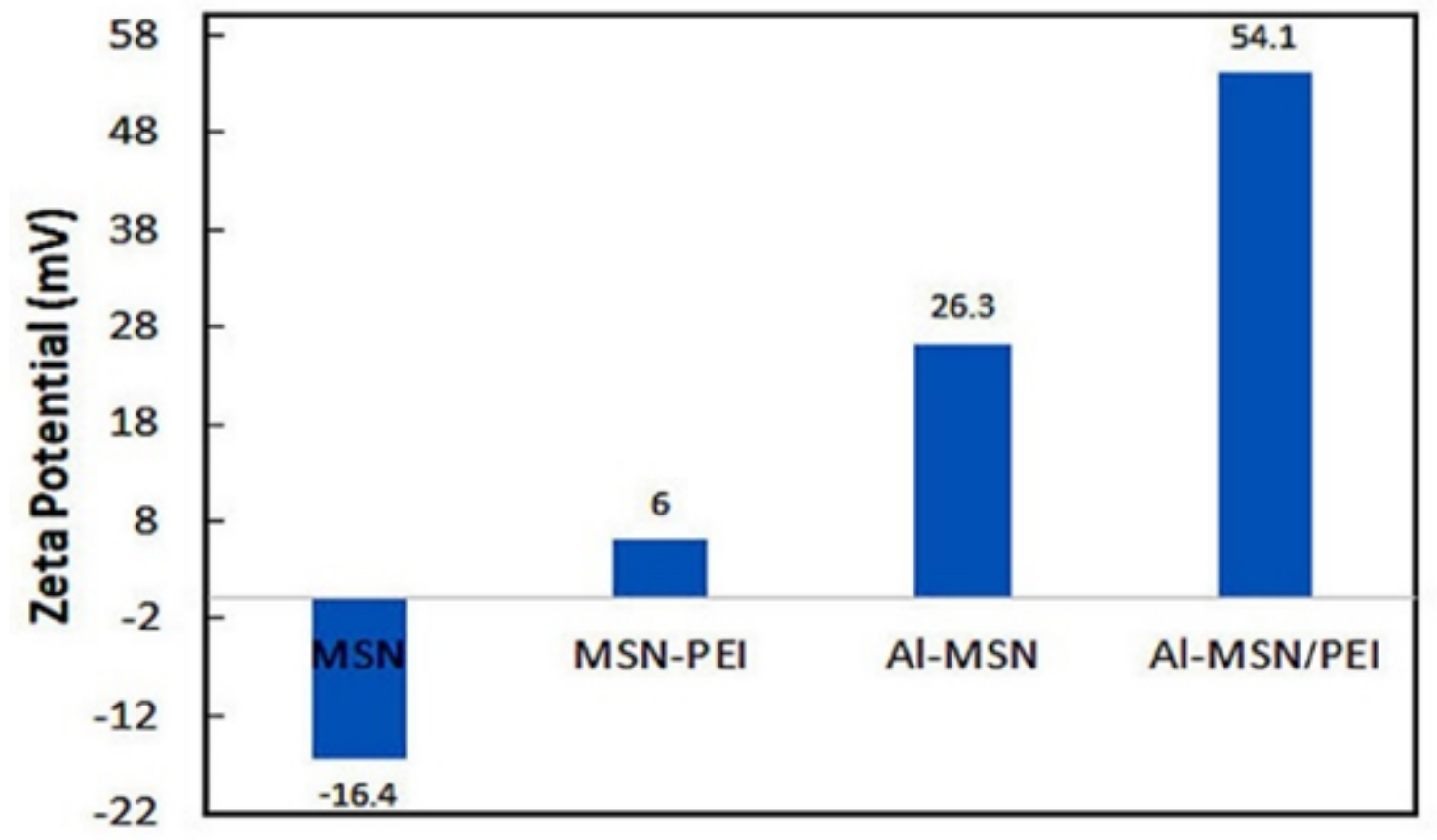

Figure 6 
Zeta potential values of the MSN, MSN-PEI, Al-MSN, and AI-MSN/PEI

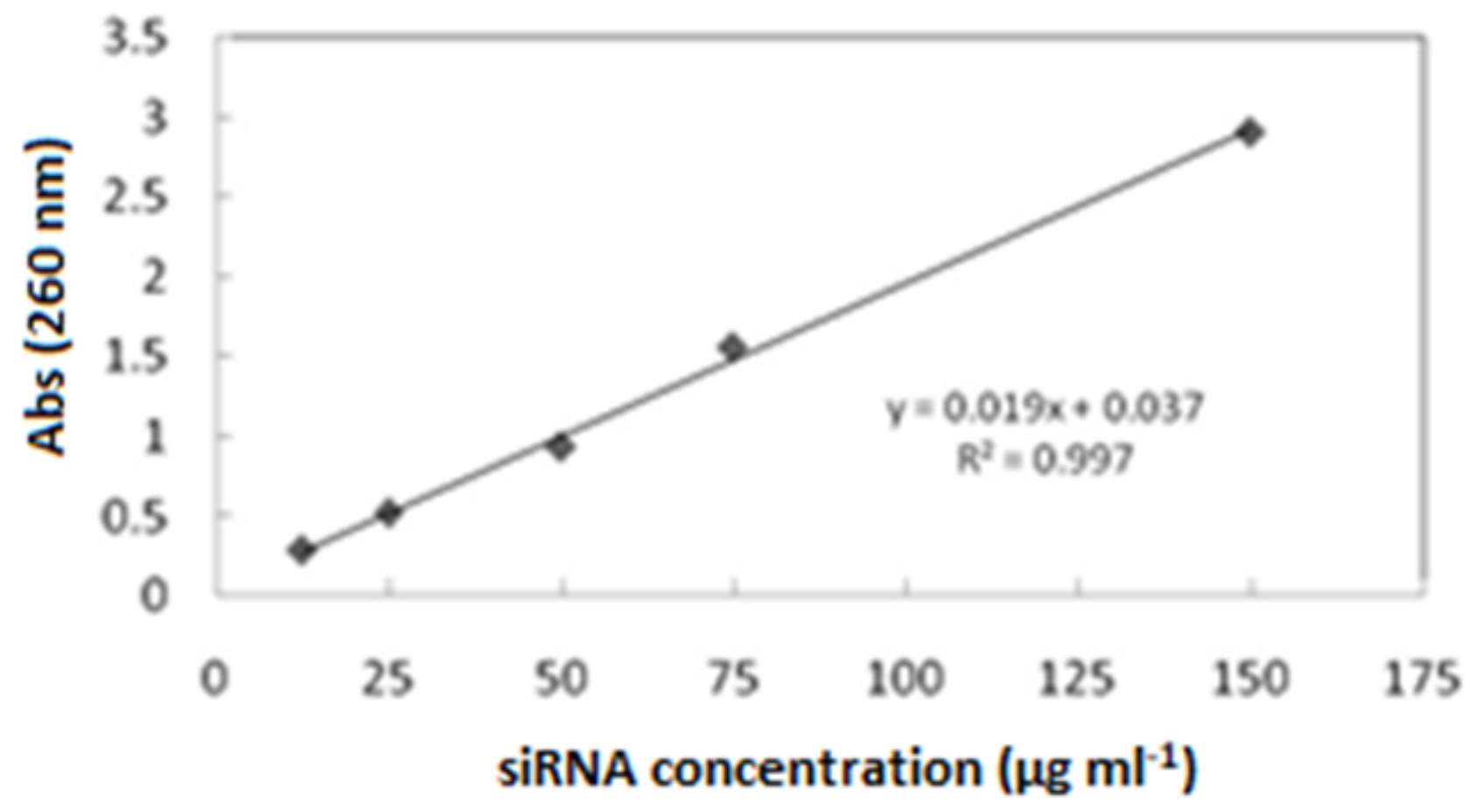

Figure 7

The calibration curve for determination of the siRNA

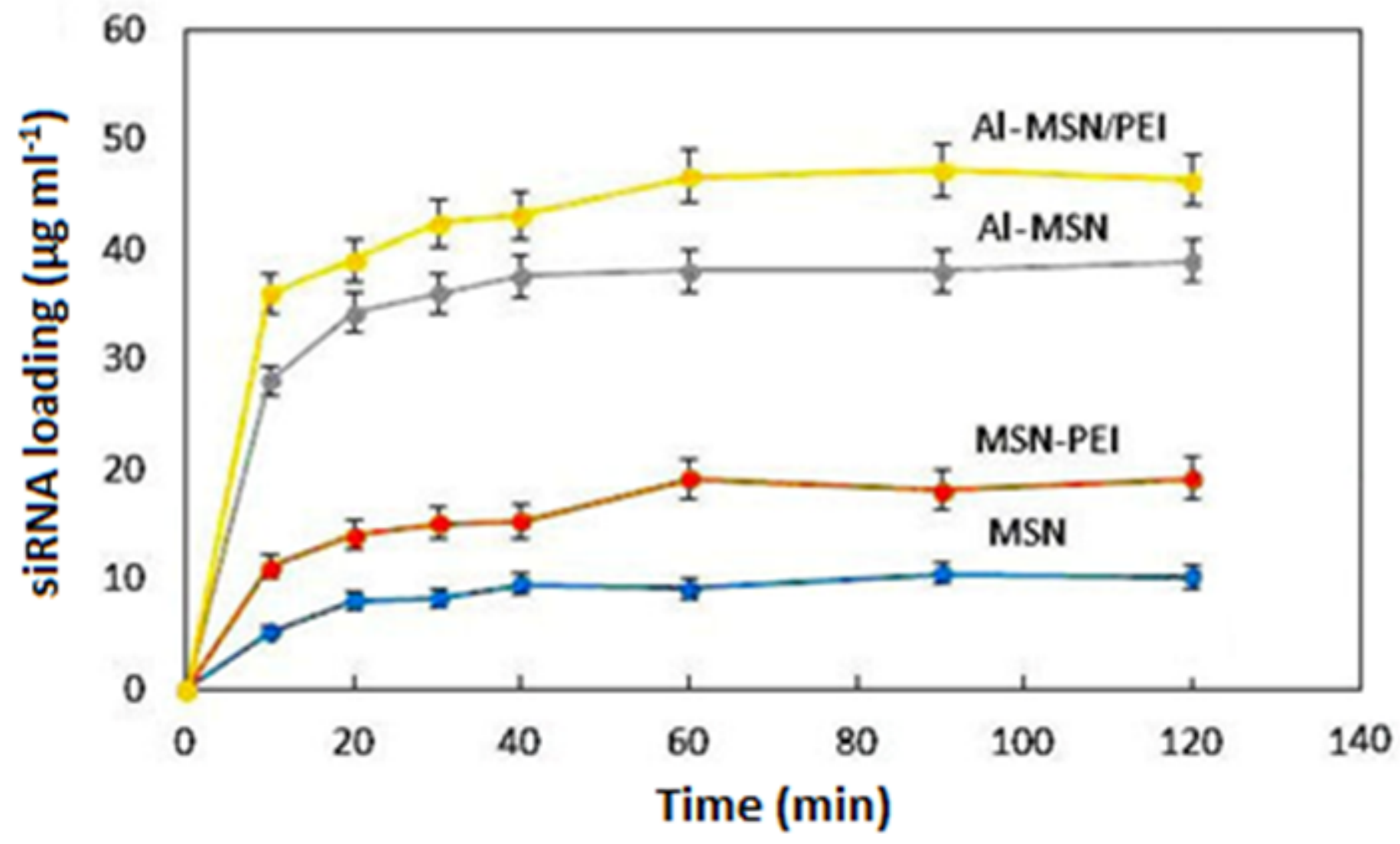

Figure 8 
Incorporation of the siRNA on the MSN, MSN-PEI, Al-MSN, and Al-MSN/PEl samples for 120 min

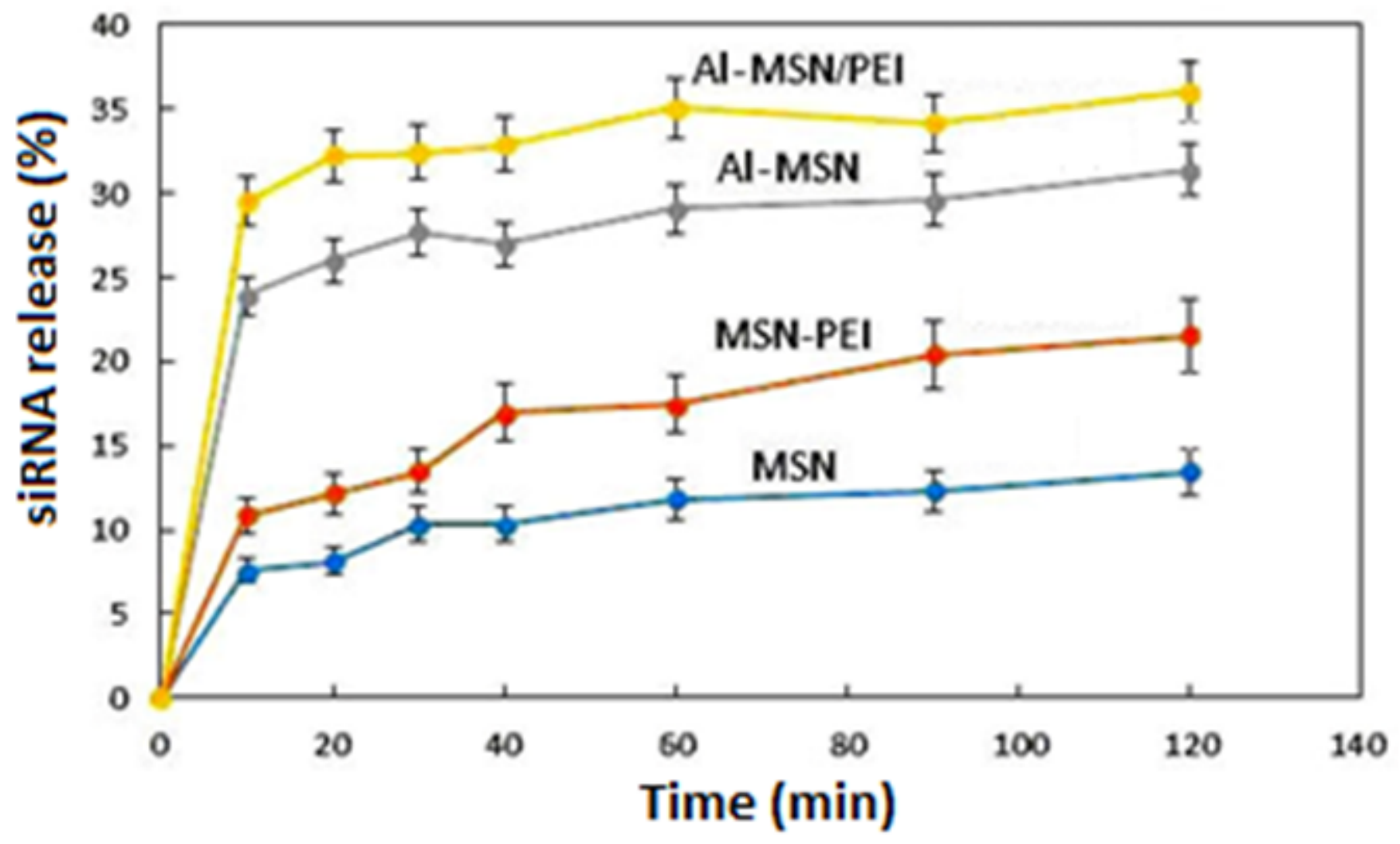

Figure 9

Desorption efficiency of the MSN, MSN-PEI, Al-MSN, and Al-MSN/PEl at room temperature for $120 \mathrm{~min}$ 